\title{
Waning immunity against mumps in vaccinated young adults, France 2013
}

S Vygen ${ }^{123}$, A Fischer ${ }^{13}$, L Meurice ${ }^{1}$, I Mounchetrou Njoya ${ }^{4}$, M Gregoris ${ }^{5}$, B Ndiaye ${ }^{6}$, A Ghenassia ${ }^{6}$, I Poujol 7 , JP Stahl ${ }^{8}$, D

Antona ${ }^{9}$, Y Le Strat ${ }^{10}$, D Levy-Bruhl ${ }^{911}$, P Rolland ${ }^{11}$

1. French Institute for Public Health Surveillance (InVS), Department of Coordination of Alerts and Regions (DCAR), Regional office in Aquitaine

2. European Program for Intervention Epidemiology Training (EPIET), European Centre for Disease Prevention and Control (ECDC)

3. Both authors contributed equally as first authors

4. InVS, DCAR, Regional office Ile-de-France and Champagne-Ardenne, Chalons en Champagne, France

5. Regional health authority (ARS) Champagne-Ardennes

6. InVS, DCAR, Regional office North, France

7. InVS, DCAR, Regional office Rhône-Alpes, France

8. University hospital Grenoble, Hôpital A. Michallon, Boulevard de la Chantourne, La Tronche, France

9. InVS, Department of infectious diseases, Unit of respiratory and vaccine preventable diseases, France

10. InVS, Department of infectious diseases, France

11. Both authors contributed equally as last authors

Correspondence: Sabine Vygen (vygen-bonnets@rki.de)

Citation style for this article:

Vygen S, Fischer A, Meurice L, Mounchetrou Njoya I, Gregoris M, Ndiaye B, Ghenassia A, Poujol I, Stahl J, Antona D, Le Strat Y, Levy-Bruhl D, Rolland P.

Waning immunity against mumps in vaccinated young adults, France 2013. Euro Surveill. 2016;21(10): pii=30156. DOI: http://dx.doi.org/10.2807/1560-7917.

ES.2016.21.10.30156

Article submitted on 21 April 2015 / accepted on 19 October 2015 / published on 10 March 2016

In 2013, 15 clusters of mumps were notified in France; $72 \%(82 / 114)$ of the cases had been vaccinated twice with measles-mumps-rubella vaccine. To determine whether the risk of mumps increased with time since the last vaccination, we conducted a case-control study among clusters in universities and military barracks. A confirmed case had an inflammation of a salivary gland plus laboratory confirmation in 2013. A probable case presented with inflammation of a salivary gland in 2013 either lasting for $>\mathbf{2}$ days or with epidemiological link to a confirmed case. Controls had no mumps symptoms and attended the same university course, student party or military barracks. We collected clinical and vaccination data via web questionnaire and medical records. We calculated adjusted odds ratios (aOR) using logistic regression. 59\% $(50 / 85)$ of cases and $62 \%(199 / 321)$ of controls had been vaccinated twice. The odds of mumps increased for twice-vaccinated individuals by $10 \%$ for every year that had passed since the second dose (aOR 1.10; $95 \%$ confidence interval $(\mathrm{CI}): 1.02-1.19 ; \mathrm{p}=0.02)$. Mumps immunity waned with increasing time since vaccination. Our findings contributed to the French High Council of Public Health's decision to recommend a third MMR dose during outbreaks for individuals whose second dose dates $>10$ years.

\section{Introduction}

Mumps is a vaccine-preventable disease caused by an RNA virus of the paramyxoviridae family [1]. Typically, patients present with a febrile painful inflammation of a parotid gland $[2,3]$. The disease is generally benign with a spontaneous resolution but can lead to serious complications, notably in adult patients, such as orchitis, meningitis, pancreatitis or encephalitis $[2,3]$.

In France, mumps vaccination was first introduced into the childhood vaccination programme at the age of one year in 1986 with a trivalent measles-mumps-rubella (MMR) vaccine, containing the Urabe strain. Since 1993 a trivalent vaccine containing the Jeryl Lynn strain has been used [4]. In 1996, a second dose was added for children aged 11-13 years [5]. The vaccination schedule was modified in the following years. In 1997, the age for the second dose was changed to 3-6 years [4] with a catch-up at 11-13 years for unvaccinated children. From 2005, the second dose was recommended in the second year of life, together with an extension of the catch-up for all individuals born from 1980 onwards [6]. However, for individuals born between 1980 and 1992, one dose was considered sufficient. Since 2012, catch-up vaccination has been recommended with two doses for all individuals born from 1980 onwards [6]. A 2008-2009 school-based survey indicated that MMR vaccination coverage for children aged 15 years in France was $96 \%$ for the first and $84 \%$ for the second dose [7]. Data for vaccination coverage of young adults (over 15 years old) are not routinely collected in France.

Notification of mumps is not mandatory in France. However, as for all infectious diseases, unusual clusters of cases must be reported to the regional health authorities, which then inform the French Institute of Public Health Surveillance (InVS). Since 1985, mumps 
Selection procedure for mumps cases and controls, case-control study among young adults, France, 2013

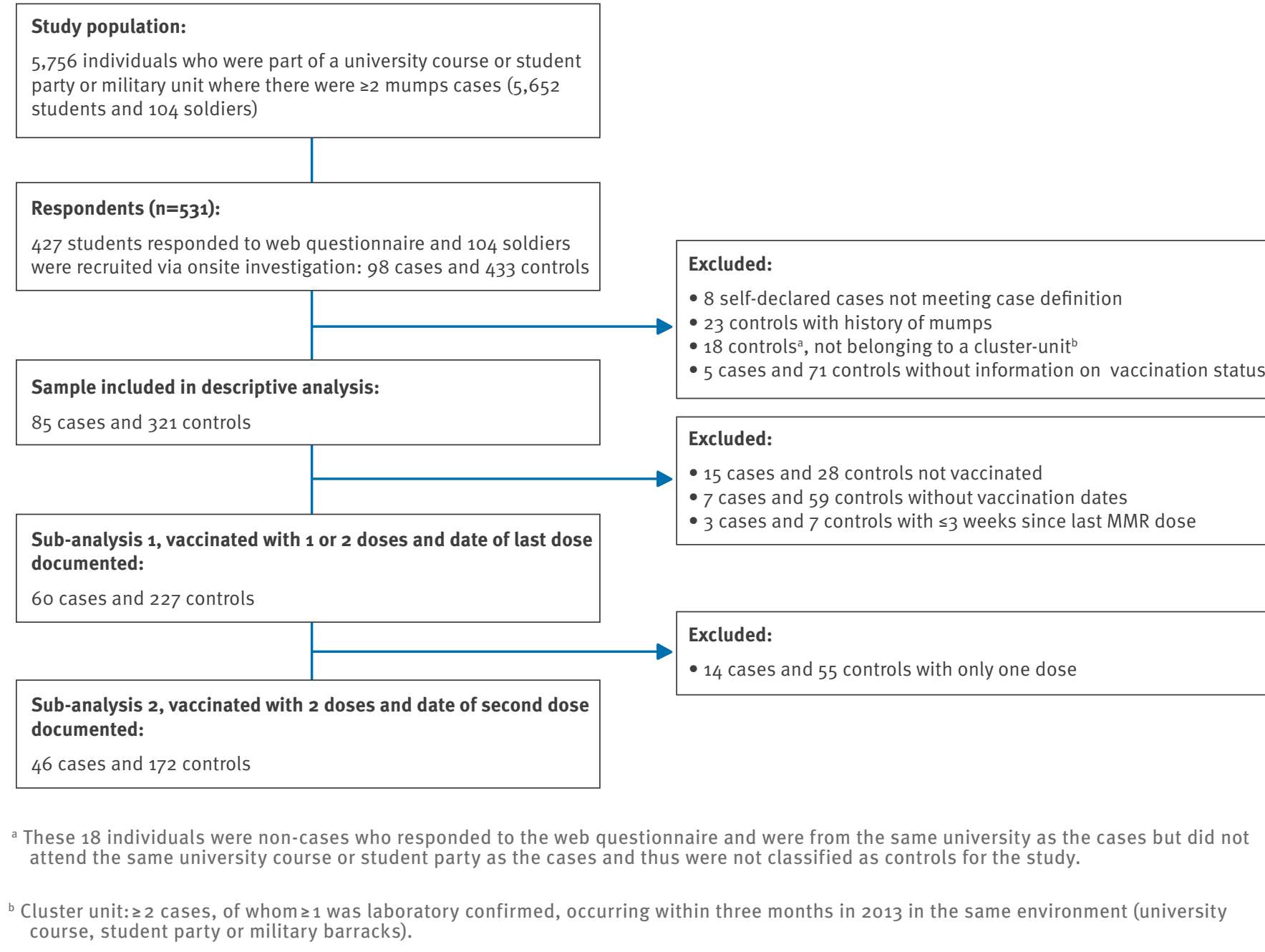

Cluster unit: $\geq 2$ cases, of whom $\geq 1$ was laboratory confirmed, occurring within three months in 2013 in the same environment (university
course, student party or military barracks).

cases have been monitored by a sentinel network of general practitioners using a clinical case definition [2,8]. Between 1986 and 2012, mumps incidence recorded by the sentinel network decreased from 859 cases per 100,000 to 6 cases per $100,000[1,2,8]$.

In the spring of 2013, an upsurge of the disease was observed in mainland France. Clusters among adolescents (11-17 years old) and young adults (18-29 years old), a majority of whom had been vaccinated with two doses of MMR, were reported to InVS. Of those, 15 clusters of between 2 and 19 cases were among university students and soldiers in five regions (out of 22 regions in metropolitan France): Aquitaine, Champagne-Ardenne, Ile-de-France, Nord Pas-de-Calais and Rhône-Alpes. Similar outbreaks among highly vaccinated young adults have occurred in other countries during the past decade (e.g. Ireland from 2004 to 2008, Moldova and the United States (US) in 2008, the Netherlands from 2009 to 2012, Israel in 2011) [2,9-12]. Those outbreaks were attributed to the accumulation of susceptible individuals in settings with opportunities for intense exposures (high level of proximity among people) and potential waning of vaccine-conferred immunity with time [13-16]. We aimed to determine whether the risk of mumps increases with an increasing interval of time since the last dose of MMR vaccination.

\section{Methods}

\section{Study design}

We conducted a multicentre case-control study with four regional offices of InVS and included all clusters notified in those regions between January and July 2013.

\section{Study population}

The study population was young adults who belonged to a mumps cluster or attended either the same university course or student party or were part of the same military unit.

\section{Definitions}

A cluster was defined as $\geq 2$ cases, of whom minimum one was laboratory confirmed, occurring within 3 
TABLE 1

Characteristics and symptoms of mumps cases, casecontrol study among young adults, France $2013(\mathrm{n}=85)$

\begin{tabular}{|c|c|c|c|}
\hline \multicolumn{2}{|l|}{ Characteristics of cases } & $\mathrm{n}$ & $\%$ \\
\hline Location of cluster unit ${ }^{a}$ & $\begin{array}{l}\text { University } \\
\text { Military barracks }\end{array}$ & $\begin{array}{l}61 \\
24\end{array}$ & $\begin{array}{l}72 \\
28\end{array}$ \\
\hline Case classification & $\begin{array}{l}\text { Probable case } \\
\text { Confirmed case }\end{array}$ & $\begin{array}{l}51 \\
34 \\
\end{array}$ & $\begin{array}{l}60 \\
40 \\
\end{array}$ \\
\hline Clinical symptoms & $\begin{array}{l}\text { Parotitis } \\
\leq 2 \text { days } \\
>2 \text { days } \\
\text { Inflammation of a sub- } \\
\text { maxillary gland }\end{array}$ & $\begin{array}{l}83 \\
24 \\
59 \\
2\end{array}$ & $\begin{array}{l}98 \\
29 \\
71 \\
2.4\end{array}$ \\
\hline Complications & Orchitis $^{b}$ & 5 & 8.8 \\
\hline Biological test & $\begin{array}{l}\text { Positive serology } \\
\text { Positive saliva PCR }\end{array}$ & $\begin{array}{l}31 \\
12\end{array}$ & $\begin{array}{l}37 \\
14\end{array}$ \\
\hline
\end{tabular}

a Cluster unit: $\geq 2$ cases, of which at least 1 was laboratory confirmed, occurring within 3 months in 2013 in the same environment (university course, student party or military barracks).

${ }^{b}$ Percentage of male cases only $(n=57)$.

months in 2013 in the same living environment (cluster unit).

A confirmed case was defined by the clinical symptoms (inflammation of a salivary gland) plus a laboratory confirmation (PCR from saliva and/or serology) in 2013. A probable case was an individual with (i) uni- or bilateral parotitis (self-reported or reported by doctor in medical records) in 2013 with duration of $>2$ days or (ii) with a reported epidemiological link to a case if the duration was $\leq 2$ days or (iii) if another salivary gland was involved.

A possible case was a person reporting a parotitis or inflammation of the sub-maxillary gland in 2013, but not fulfilling the criteria for a probable or a confirmed case.

\section{Recruitment of controls}

For the cases in students, we chose as controls all students without any reported symptoms of mumps who responded to the web questionnaire (see below) and who attended the same university courses or student party as the cases. For the cases in soldiers, we chose as controls all soldiers from the same unit within the military barracks as the cases, and who had no recorded history of mumps. We aimed to have at least three controls per case.

\section{Inclusion and exclusion criteria}

We included only clusters for which we could obtain at least one control per case and all probable and confirmed cases that belonged to a cluster unit. We excluded possible cases in order to increase specificity and individuals without or with incomplete information on vaccination status. We excluded individuals who were vaccinated against mumps within 3 weeks before the onset of mumps or within 3 weeks before recruitment as controls.

\section{Data collection}

Via email, we invited all students from each university course with a mumps cluster to respond to a webbased questionnaire, using Voozanoo 123 software (Epiconcept SA, France). We re-contacted individuals by telephone and email to complete missing data whenever possible. In some regions we visited universities in order to encourage participation.

Data from soldiers were collected via individual medical records and vaccination booklets during a visit to the barracks.

The questionnaire, which was completed by the students, or by the investigators on behalf of the soldiers, covered demographic information, details about the cluster unit, mumps symptoms (self-reported for the university students and recorded by a medical doctor for the military personnel), laboratory test results, vaccination history and the source of vaccination information (vaccination or health booklet, distributed at birth in France including all childhood vaccination records; medical files for soldiers).

\section{Data analysis}

We described probable and confirmed cases and controls (demographic data, cluster unit, vaccination status, and additionally for cases, symptoms, biological tests and case classification). Characteristics of cases and controls (age at the time of the study and at first MMR dose, sex, vaccination status, time interval between MMR doses) were compared using logistic regression. Vaccine effectiveness (VE) was calculated for one and two doses compared with unvaccinated individuals, according to the formula: $\mathrm{VE}=(1-\mathrm{OR})$ * 100 , with the OR calculated by multivariate regression adjusted for sex.

For further analysis, we included only individuals for whom vaccination dates were recorded in a document. We calculated the mean number of years since the last dose for cases and controls. We used a multivariate logistic regression model for testing the association between the onset of mumps and the time since the last dose expressed as adjusted odds ratio (aOR). Time was modelled with a fractional polynomial. For cases and controls who had received at least one dose of vaccine, we adjusted for sex, age, cluster unit and number of MMR doses received. Independently, we looked only at cases and controls who had received two doses and adjusted for sex, age and cluster unit.

We described means and interquartile ranges (IQR) of the time interval between two doses for cases and controls and compared the intervals between the two groups using logistic regression. 
TABLE 2

Characteristics of mumps cases and controls, case-control study among young adults, France, 2013

\begin{tabular}{|c|c|c|c|c|c|c|}
\hline & \multirow[t]{2}{*}{ Number of clusters } & \multicolumn{2}{|c|}{$\begin{array}{c}\text { Cases } \\
(\mathrm{N}=85)\end{array}$} & \multicolumn{2}{|c|}{$\begin{array}{l}\text { Controls } \\
(\mathrm{N}=321)\end{array}$} & \multirow[t]{2}{*}{$p^{b}$} \\
\hline & & $\mathrm{n}$ & $\%$ & $\mathrm{n}$ & $\%$ & \\
\hline \multicolumn{7}{|l|}{ Location of cluster unit ${ }^{a}$} \\
\hline Military barracks & 2 & 24 & 28 & 78 & 24 & \multirow{6}{*}{$0.07^{c}$} \\
\hline University in Pau & 2 & 8 & 9.4 & 19 & $5 \cdot 9$ & \\
\hline University in Lille & 2 & 10 & 12 & 39 & 12 & \\
\hline University A in Grenoble & 4 & 26 & 31 & 74 & 23 & \\
\hline University B in Grenoble & 1 & 4 & $4 \cdot 7$ & 4 & 1.3 & \\
\hline University and student party in Reims & 2 & 13 & 15 & 107 & 33 & \\
\hline \multicolumn{7}{|l|}{ Sex } \\
\hline Men & NA & 57 & 67 & 176 & 55 & 0.04 \\
\hline \multicolumn{7}{|l|}{ MMR vaccination status } \\
\hline Not vaccinated & NA & 15 & 18 & 28 & 8.7 & \multirow{4}{*}{$0.06^{d}$} \\
\hline 1 dose & NA & 17 & 20 & 61 & 19 & \\
\hline 2 doses & NA & 50 & 59 & 199 & 62 & \\
\hline Number of doses unknown & NA & 3 & 3.5 & 33 & 10 & \\
\hline \multicolumn{7}{|l|}{ Time interval between doses } \\
\hline Mean (IQR) & NA & \multicolumn{2}{|c|}{$7.7(3.3-10.0)$} & \multicolumn{2}{|c|}{$7.9(5.1-10.0)$} & 0.99 \\
\hline \multicolumn{7}{|l|}{ Age in years (mean and IQR) } \\
\hline At the first MMR dose & NA & \multicolumn{2}{|c|}{$2.9(1-2)$} & \multicolumn{2}{|c|}{$3.9(1-4)$} & 0.22 \\
\hline At time of study & NA & \multicolumn{2}{|c|}{$21.8(21-23)$} & \multicolumn{2}{|c|}{$21.4(20-22)$} & 0.08 \\
\hline
\end{tabular}

IQR: interquartile range; MMR: measles-mumps rubella vaccine; NA: not applicable.

a Cluster unit: $\geq 2$ cases, of which $\geq 1$ was laboratory confirmed, occurring within 3 months in 2013 in the same environment (university course, student party or military barracks)

${ }^{b}$ All p-values are derived by logistic regression

c Comparison refers to the 13 cluster units

${ }^{\mathrm{d}}$ Comparison includes only individuals with zero, one or two doses

Based on the recommendation of the French High Council of Public Health (HCSP) to administer a third dose in outbreak settings to all individuals whose last MMR dose was more than 10 years ago [17], we specifically looked at the interval of 10 years since the second MMR dose.

A two-sided $p$-value of $<0.05$ was considered statistically significant. Analyses were performed using Stata version 12.0 (StataCorp, College Station, Texas, US).

\section{Results}

\section{Recruitment of cases and controls}

Thirteen clusters with 2 to 19 cases were included. Two clusters could not be included due to organisational issues. Clusters were reported in five universities and two units of the same military barrack. Of the 5,652 students invited, 427 responded to the web-based survey (response $8 \%$ ). Of those, 72 students declared themselves as cases and 355 were classified as controls. Sixty-one met the definition of a probable $(n=47)$ or a confirmed case $(n=14)$. In addition, we recruited 104 individuals (20 confirmed cases, 6 probable cases and 78 controls) from the military (inclusion 96\%). The initial database included 98 probable and confirmed cases (self-reported or diagnosed by a military doctor) and 433 controls (Figure). This corresponds to $51 \%$ (98/194) of the initially reported cases. Individuals with no information on vaccination status were excluded. In addition, we excluded from the analysis eight selfdeclared cases who did not meet the definition of a probable or confirmed case and 112 controls, either because they did not meet the definition of a control or because they had a history of mumps in the past. In total, 85 cases and 321 controls were included in the descriptive part of the study. For the logistic regression model we excluded individuals who were not vaccinated $(n=43)$, who did not have their vaccination dates documented $(n=66)$ and those who had received their last dose of $M M R \leq 3$ weeks before the study $(n=10)$.

\section{Description of cases and controls}

Ninety-eight per cent of cases (83/85) presented with parotitis; two suffered from an inflammation of a submaxillary gland and had a positive serology, one also had a positive PCR. The only complication reported was orchitis (Table 1). Among the five men who presented with orchitis (of 57 male cases), one had not been vaccinated; two were vaccinated with one MMR dose and two with two doses. Fifty of the $61(82 \%)$ cases among university students reported that they had at least 
one contact with at least one case before developing mumps.

Cases were more likely to be males than controls $(p=0.04)$ (Table 2$)$. Cases and controls did not differ significantly in terms of age. There were more unvaccinated cases than controls, $18 \%(15 / 85)$ vs $9 \%$ (28/321), but the proportion of cases and controls vaccinated with two doses was similar, 59\% (50/85) vs $62 \%$ (199/321) (Table 2). Nobody had received more than two doses. Vaccine effectiveness among individuals who had received only one dose was 49\% (adOR $0.51 ; 95 \% \mathrm{Cl} 0.2-1.2$ ) and $55 \%$ for two doses (adOR $0.45 ; 95 \% \mathrm{Cl} 0.2-0.9)$, compared with unvaccinated individuals.

Association between the time since the last measles-mumps-rubella vaccine dose and the onset of mumps

The best-fitting fractional polynomial was a linear transformation of the time. This transformation was thus kept for further analysis.

Respondents with one or two measles-mumpsrubella vaccine doses

When we restricted the analysis to the 60 cases and 227 controls who had received at least one dose of MMR vaccination and for whom at least the date of the last dose was documented, the mean time from the last dose to symptom onset was 13 years (IQR 11-15 years) for cases and from the last dose to the moment of study participation, 12 years (IQR 9-15 years) for controls. Adjusting for age, sex, cluster unit and number of MMR doses, the odds of mumps increased by $7 \%$ for every additional year in time since their last MMR dose (aOR: 1.07; 95\%Cl: 1.01-1.14).

\section{Respondents with two measles-mumps-rubella vaccine doses \\ We further restricted the analysis to the 46 cases and 172 controls who had two documented doses of MMR. Of those, 25 individuals ( 21 soldiers and 4 students) had received their second dose less than one year before the study began. The minimum time interval between two doses was 28 days. Time intervals between doses and the age at the first dose were not significantly dif- ferent between cases and controls (Table 2). The mean time from the second dose to symptom onset was 12 years (IQR 11-14 years) for cases and from the second dose to the moment of study participation 11 years (IQR 9-14 years) for controls.}

Adjusting for age, sex, and cluster unit, the odds of mumps increased by $10 \%$ for every year increase in time since the second dose (aOR 1.10; $95 \% \mathrm{Cl}: 1.02-$ 1.19). This odds increased by $162 \%$ (aOR $2.62 ; 95 \% \mathrm{Cl}$ 1.9-5.8) for 10 years since the second dose, based on 46 cases and 172 controls.

\section{Discussion}

Mumps outbreaks occurred in France in 2013 in highly vaccinated young adults. We describe an association between the time interval since the last dose of $M M R$ vaccination and disease onset, with the odds of the disease increasing with increasing time since last vaccination. This suggests waning mumps-vaccineconferred immunity over time. The result was obtained using a logistic regression model. We also calculated incidence rate ratios using a Poisson regression model with a robust error variance (data not shown). We obtained similar results as with the logistic regression model, and thus we decided to keep the simpler model and to report ORs.

Our findings are consistent with observations of mumps outbreaks among highly vaccinated young adults in many countries in recent years, suggesting secondary vaccine failure: in Ireland (2004-05) [18], the US (2006 and 2009-10) [3,10,16,19], England and Wales (2011) [14], Serbia (2012) [20] and the Netherlands (2013) [9]. Waning vaccine-conferred immunity in the absence of natural boosters in individuals who had received their last MMR dose many years before was suggested as one of the most important reasons contributing to the occurrence of outbreaks in highly vaccinated populations $[9,14,16,21]$. A combination of other suggested reasons included a lower-than-expected vaccine effectiveness [21], insufficient two-dose vaccination coverage $[13,18]$, short time interval between MMR doses [22], intense proximity in semi-closed populations $[3,9,10,21]$, and mismatch of the vaccine virus strain with the circulating outbreak strains [21,23]. Several studies $[15,16,24]$ indicated a high attack rate in individuals who were vaccinated more than 10 years previously. However, in most studies which evaluated the effect of time since MMR vaccination, cases' age groups or birth cohorts were used as a proxy for the number of years since the last dose $[22,25,26]$ assuming good adherence to national vaccination recommendations. Our study provides more robust evidence of waning immunity, as our estimates were based on actual vaccination dates. Since the MMR vaccination schedule in France has changed several times during the childhoods of the population concerned, including catchup vaccinations at different time points, we could not assume uniform vaccination history. Those differences of the second dose's timing, even within the same birth cohort, allowed us to measure the association between timing of the second dose and disease onset. We did not find any significant difference between cases and controls in the time intervals between the two doses. In a model without the variable 'time since last dose', the variable 'age at first dose' was associated with mumps occurrence (data not shown). However, when including both variables in a model, none of the aORs was statistically significant, even though both point estimates were only slightly modified. We concluded that the reason for not getting significant results when we are including both variables in the same model is mainly a lack of statistical power and that both variables are 
independently associated with the outcome. A recent study of measles showed an association between age at first MMR dose and measles occurrence [27], which may possibly apply to mumps too and deserves further investigation. In similar future studies, which may include a larger number of individuals, adjustment for age at the first dose should be undertaken.

A further limitation of our study is the fact that vaccination history was self-reported by the students. To reduce inaccuracy and to obtain reliable information on vaccination history, only students who documented vaccination dates according to their vaccination or health booklets were included in the analytical part of the study. The low response to the online survey at the universities may be due to the fact that we surveyed the students 1 to 4 months after the start of the different outbreaks and after initial investigations had already been carried out. It is conceivable that controls who had recently been vaccinated had a greater awareness of the topic and responded more willingly than individuals whose vaccination was longer ago. To limit this possible participation bias and increase response, we contacted students repeatedly by email and telephone and visited some of the universities. Symptoms were also self-reported by the students which might have led to over-reporting of disease. To increase specificity, we only included probable and confirmed cases and requested at least one laboratory-confirmed case per cluster. Due to the nature of the organisation of the army, there was a higher percentage of laboratoryconfirmed cases among soldiers than among students. For the soldiers, the investigators were able to consult laboratory results in the medical files. Students self-reported their biological confirmation. This is a difference in reliability between data of soldiers and students, but outbreak investigation teams who had undertaken site visits to the universities in order to confirm the outbreak before the study had seen the laboratory results of the initial cases.

In older age groups, complications of mumps are more frequent and more severe than in children $[2,14]$. This is especially true for unvaccinated individuals $[9,14]$. Before the introduction of MMR vaccination, mumps was the primary cause of viral meningitis and a leading cause of hearing loss in children $[28,29]$. In our study, we observed few complications (orchitis in $9 \%$ of male cases). The small size of our study did not allow detection of differences in complication rates by vaccination status. However, the low overall incidence of complications is in line with what was described after introduction of MMR vaccination by previous studies $[3,10]$. In an outbreak in the Netherlands in 2013 among a predominantly vaccinated population $(78 \%$ one-dose vaccination coverage), orchitis and all-cause hospitalisations were significantly lower in individuals vaccinated with one dose and lower still in those vaccinated twice [9]. Similar findings were described in England and Wales (in 2004-2005) [14]. This suggests that although mumps vaccination may not confer long-term protection against the disease, a previously vaccinated individual is able to mount a rapid immune response which is sufficient to reduce complications significantly [14].

Age at mumps infection in France, as well as in other countries, has shifted from childhood to adolescence and young adulthood following the introduction of MMR vaccination in the routine childhood immunisation schedules $[2,9,10,14,18]$. The majority of cases in our study population were vaccinated in childhood and had low residual protection in young adulthood, with little difference between those who had received one or two doses. The relatively high number of individuals who got their second dose during the year before the study is related to the fact of most of them were young soldiers who had their vaccination status reviewed and updated when entering the army. In France, people born before the 1980 s were not vaccinated against mumps. However, due to the wide circulation of the virus in the community before the introduction of vaccination, they are likely to have had natural mumps infection and have thus acquired long-lasting protection. In 2013, at the time of the occurrence of the described clusters, those individuals born before the 1980 s were $\geq 33$ years old and no cases were reported among them. Only young adults (the mean age of cases was 22 years) in environments prone to intense social mixing were included in the study. Extrapolation of our results to other populations needs to be undertaken with great caution.

One of the possible responses to confer a better level of immunity in young adults could be to postpone the administration of the second MMR dose until later in adolescence [21]. However, we observed a very low one-dose VE (48\%) in our study population and VE in the general population is reported to be between $62 \%$ and $85 \%$ [15]. This low VE and the fact that the vaccine is commonly administered in combination with measles and rubella vaccines do not favour such approach. Likewise, we cannot hope for the availability of a vaccine with a higher effectiveness in the near future.

Waning mumps-vaccination-conferred immunity and the occurrence of outbreaks in highly vaccinated populations suggest the need for a third MMR dose. The administration of a targeted third dose in schools has been experimented with in the US during two outbreaks in 2009 and 2010 [3,19]: In both instances attack rates declined markedly during the weeks following the intervention. However, the decline in the number of new cases may have been partly attributable to the natural dynamics of the epidemics. Nevertheless, those and other experiences suggest that a third-dose intervention may be an appropriate measure to limit the propagation of outbreaks and a good control measure in highly vaccinated, relatively closed populations. In addition, low rates of vaccination side effects of a third dose were reported in both studies $[3,19]$. This seems plausible as the vaccine virus will rapidly be inactivated 
by pre-existing antibodies when administering a live attenuated vaccine to a person with remaining immunity from a previous vaccination.

The Netherlands has considered the introduction of a regular third dose in the national vaccination schedule but abandoned the idea because mumps-associated morbidity was relatively low and vaccine uptake of a third dose was unlikely to be satisfactory [9].

Since 1991, all new recruits to the US army receive a MMR vaccination regardless of their previous vaccination status and thus, in many cases, a third dose. Before 1991, outbreaks regularly occurred among US soldiers [30]. During the 2006 outbreak in the US, which involved mainly adults aged 18 to 24 years, not a single case in this age group was reported in American troops [31]. However, the American recommendation is limited to army personnel.

Following the upsurge of mumps in 2013, and taking into consideration the high proportion of cases vaccinated with two doses, the French HCSP has recommended a third dose in outbreak settings involving semi-closed populations (schools, universities, boarding schools, barracks, sport clubs, etc.) for individuals vaccinated $>10$ years earlier [17]. Our preliminary study results substantiated this decision. This recommendation goes alongside catch-up vaccination of non- or partially vaccinated individuals.

The third-dose strategy will not prevent disease in already-infected contact persons, but rather limit the size of the outbreak and avoid further spread. In addition to avoiding further cases, the third dose might help to limit complications. Although there is no good evidence for the usefulness of the vaccination in individuals who are already incubating the virus, a shortening of the period of virus shedding is conceivable [32]. In addition to the above-mentioned limitations, controls' probability of exposure to the virus may have been overestimated if contact with cases was not as close as assumed. Most cluster units had a high number of cases and in most universities we found clusters in different courses or years. We thus considered viral circulation as sufficiently dense to make the assumption that cases and controls had equal probability of being exposed. The number of asymptomatically infected individuals was probably not negligible. In a serological study from the Netherlands, investigating mumps antibody titres before and after an outbreak, the authors showed an attack rate almost two-fold higher in asymptomatic individuals compared with symptomatic persons [33]. However, the role of asymptomatically infected individuals for transmission remains unclear.

Strain identification of the virus would have been additional interesting information. However, this was beyond the scope of this study.
Our study suggests that mumps vaccine effectiveness wanes with time. Our findings substantiate the introduction of a targeted third dose in outbreak settings for individuals with $>10$ years after the last dose. Future observations in France and possibly other countries which might introduce the same recommendation or a recommendation with different inclusion criteria for a third dose, will determine whether the approach of a third MMR dose is an effective public health intervention for limiting mumps outbreaks.

\section{Acknowledgements}

Fabrice Castel (specialised medical facility of the French armed forces, Souges, France), Olivier Catelinois (coordinator of the regional office of the French Institute of Public Health Surveillance (InVS)/Rhône-Alpes, DCAR, France), Pascal Chaud (coordinator of the regional office of InVS/ Nord, DCAR, France), Kostas Danis (European program for intervention epidemiology training (EPIET); InVS Saint Maurice, France), Patrick Derain (regional management of health services of the French armed forces, Bordeaux, France), Aïssata Dia (centre for epidemiology and public health of the French armed forces, Marseille, France), Laurent Journaux (specialised medical facility of the French armed forces, Bayonne, France), Stéphanie Vandentorren (coordinator of the regional office of InVS/Ile-de-France, Paris and Champagne-Ardenne, DCAR, France).

\section{Conflict of interest}

None

Authors' contributions

Sabine Vygen: procotol writing, carrying out of the survey. Sabine Vygen and Aurélie Fischer: data analysis and writing up of the manuscript. Laure Meurice, Ibrahim Mounchetrou Njoya, Marina Gregoris, Bakhao Ndiaye, Adrien Ghenassia, Isabelle Poujol: outbreak investigation and data collection in the different regions. Denise Antona, Daniel Levy-Bruhl, Jean Paul Stahl, Patrick Rolland: discussions and scientific input on procotol, data analysis and manuscript. Yann Le Strat: expertise on data analysis.

\section{References}

1. Institut de Veille Sanitaire (InVS). Dossiers thématiques; Oreillons. [Thematic dossiers; mumps]. French. [Accessed 15 Jul 2013]. Available from: http://www.invs.sante. $\mathrm{fr} /$ Dossiers-thematiques/Maladies-infectieuses/ Maladies-a-prevention-vaccinale/Oreillons

2. Coffinières $E$, Turbelin $C$, Riblier $D$, Aouba A, Levy-Bruhl D, Arena C, et al. Mumps: burden of disease in France. Vaccine. 2012;30(49):7013-8. DOI: 10.1016/j.vaccine.2012.09.070 PMID: 23059354

3. Nelson GE, Aguon A, Valencia E, Oliva R, Guerrero ML, Reyes $R$, et al. Epidemiology of a mumps outbreak in a highly vaccinated island population and use of a third dose of measles-mumps-rubella vaccine for outbreak control--Guam 2009 to 2010. Pediatr Infect Dis J. 2013;32(4):374-80. DOI: 10.1097/INF.ob013e318279f593 PMID: 23099425

4. Institut national de prévention et d'éducation pour la santé (Inpes), Paris, France. Vaccination contre les oreillons, dans Guide des vaccinations - Edition 2012, page 223-229. [Vaccination against mumps, in the guide to vaccinations edition 2012, pp. 142-8]. Paris: Inpes; 2012. French. Available from: http://www.inpes.sante.fr/10000/themes/vaccination/ guide-vaccination-2012/pdf/GuideVaccinations2012_ Vaccination_contre_les_oreillons.pdf 
5. Le calendrier des vaccinations et les recommandations vaccinales 1996-1997. [Vaccination calendar and vaccination recommendations 1996-1997]. Bull Epidemiol Hebd. 1996; 35: 151-3. French. Available from: http://www.invs.sante.fr/ beh/1996/9635/index.html

6. Institut de Veille Sanitaire. Comité technique des vaccinations, Paris, France. Calendrier des vaccinations et les recommandations vaccinales 2013 selon l'avis du Haut conseil de la santé publique. [Vaccination calendar and vaccination recommendations for 2013 according to the opinion of the High council of public health]. Bull Epidemiol Hebd 2013;14-15. French. Available from: http://www.invs.sante.fr/Publicationset-outils/BEH-Bulletin-epidemiologique-hebdomadaire/ Archives/2013/BEH-n-14-15-2013

7. Antona D, Fonteneau L, Lévy-Bruhl D, Guignon N, De Peretti $C$, Niel X, et al. Couverture vaccinale des enfants et des adolescents en France: résultats des enquêtes menées en milieu scolaire, 2001-2004. [Vaccination coverage of children and adolescents in France: results of a school survey, 20012014]. Bull Epidemiol Hebd 2007;6:45-9. French. Available from: http://www.invs.sante.fr/beh/2007/06/beh_06_2007. pdf

8. The French National Institute of Health and Medical Research (Inserm U707). University of Paris VI: Pierre and Marie Curie, Paris, France. Réseau Sentinelles [French GP sentinel network]. French. [Accessed in June 2013]. Available from: http:// websenti.u707.jussieu.fr/sentiweb/?page=bilan

9. Sane J, Gouma S, Koopmans M, de Melker H, Swaan C, van Binnendijk R, et al. Epidemic of mumps among vaccinated persons, The Netherlands, 2009-2012. Emerg Infect Dis. 2014;20(4):643-8. DOI: 10.3201/eid2004.131681 PMID: 24655811

10. Dayan GH, Quinlisk MP, Parker AA, Barskey AE, Harris ML, Schwartz JM, et al. Recent resurgence of mumps in the United States. N Engl J Med. 2008;358(15):1580-9. DOI: 10.1056/ NEJMoa0706589 PMID: 18403766

11. Eriksen J, Davidkin I, Kafatos G, Andrews N, Barbara C, Cohen D, et al. Seroepidemiology of mumps in Europe (1996-2008): why do outbreaks occur in highly vaccinated populations? Epidemiol Infect. 2013;141(3):651-66. DOI: 10.1017/ S0950268812001136 PMID: 22687578

12. Anis E, Grotto I, Moerman L, Warshavsky B, Slater PE, Lev B. Mumps outbreak in Israel's highly vaccinated society: are two doses enough?Epidemiol Infect. 2012;140(3):439-46. DOI: 10.1017/S095026881100063X PMID: 21554780

13. Dayan GH, Rubin S. Mumps outbreaks in vaccinated populations: are available mumps vaccines effective enough to prevent outbreaks?Clin Infect Dis. 2008;47(11):1458-67. DOI: 10.1086/591196 PMID: 18959494

14. Yung CF, Andrews N, Bukasa A, Brown KE, Ramsay M. Mumps complications and effects of mumps vaccination, England and Wales, 2002-2006.Emerg Infect Dis. 2011;17(4):661-7, quiz 766. DOI: 10.3201/eid1704.101461 PMID: 21470456

15. Cohen C, White JM, Savage EJ, Glynn JR, Choi Y, Andrews N, et al. Vaccine effectiveness estimates, 2004-2005 mumps outbreak, England. Emerg Infect Dis. 2007;13(1):12-7. DOI: 10.3201/eid1301.060649 PMID: 17370510

16. Marin M, Quinlisk P, Shimabukuro T, Sawhney C, Brown $C$, Lebaron CW. Mumps vaccination coverage and vaccine effectiveness in a large outbreak among college students-lowa, 2006.Vaccine. 2008;26(29-30):3601-7. DOI: 10.1016/j. vaccine.2008.04.075 PMID: 18539365

17. Haut Conseil de la santé publique (HCSP). Avis relatif à la conduite à tenir en case d'épisodes de cas groupés d'oreillons en collectivité. Paris : HCSP; 11 Jul 2013. [Opinion on the conduct to adopt in the face of episodes of clusters of mumps in institutions]. French. Available from: http://www.hcsp.fr/ Explore.cgi/avisrapportsdomaine?clefr $=364$

18. Gee S, O'Flanagan D, Fitzgerald M, Cotter S. Mumps in Ireland, 2004-2008. Euro Surveill. 2008;13(18):18857. Available from: http://www.eurosurveillance.org/ViewArticle. aspx?Articleld=18857PMID: 18768133

19. Ogbuanu IU, Kutty PK, Hudson JM, Blog D, Abedi GR, Goodell S, et al. Impact of a third dose of measles-mumpsrubella vaccine on a mumps outbreak. Pediatrics. 2012 Dec;130(6):e1567-74. Available from: http://pediatrics. aappublications.org/content/130/6/e1567.full.pdf

20. Rajčević S, Šeguljev Z, Petrovic V, Medić S, Nedelijković J, Milosević V, et al. Ongoing mumps outbreak in Novi Sad, the autonomous province of Vojvodina, Serbia, January to April 2012. Euro Surveill. 2012;17(19):20169.PMID: 22607963

21. Quinlisk MP. Mumps control today.J Infect Dis. 2010;202(5):655-6. DOI: 10.1086/655395 PMID: 20662719

22. Cortese MM, Jordan HT, Curns AT, Quinlan PA, Ens KA, Denning PM, et al. Mumps vaccine performance among university students during a mumps outbreak. Clin Infect Dis. 2008;46(8):1172-80. DOI: 10.1086/529141 PMID: 18444852

23. Gouma S, Sane J, Gijselaar D, Cremer J, Hahné S, Koopmans M, et al. Two major mumps genotype $\mathrm{G}$ variants dominated recent mumps outbreaks in the Netherlands (2009-2012). J Gen Virol. 2014;95(Pt 5):1074-82. DOI: 10.1099/vir.0.062943-0 PMID: 24603524

24. Savage E, Ramsay M, White J, Beard S, Lawson H, Hunjan R, et al. Mumps outbreaks across England and Wales in 2004: observational study. BMJ. 2005;330(7500):1119-20. DOI: 10.1136/bmj.330.7500.1119 PMID: 15891227

25. Hahné S, Whelan J, van Binnendijk R, Swaan C, Fanoy E, Boot $\mathrm{H}$, et al. Mumps vaccine effectiveness against orchitis. Emerg Infect Dis. 2012;18(1):191-3. DOI: 10.3201/eid1801.111178 PMID: 22260843

26. Ladbury G, Ostendorf S, Waegemaekers T, van Binnendijk $\mathrm{R}$, Boot $\mathrm{H}$, Hahné S. Smoking and older age associated with mumps in an outbreak in a group of highlyvaccinated individuals attending a youth club party, the Netherlands, 2012.Euro Surveill. 2014;19(16):20776. . Available from: http://www.eurosurveillance.org/ ViewArticle.aspx?Articleld=20776DOI: 10.2807/1560-7917. ES2014.19.16.20776 PMID: 24786261

27. De Serres G, Boulianne N, Defay F, Brousseau N, Benoît M, Lacoursière $S$, et al. Higher risk of measles when the first dose of a 2 -dose schedule is given at 12-14 versus 15 months of age. Clin Infect Dis. 2012;55(3):394-402. DOI: 10.1093/cid/cis439 PMID: 22543023

28. Hall R, Richards H. Hearing loss due to mumps.Arch Dis Child. 1987;62(2):189-91. DOI: 10.1136/adc.62.2.189 PMID: 3827297

29. Gupta RK, Best J, MacMahon E. Mumps and the UK epidemic 2005.BMJ. 2005;330(7500):1132-5. . Available from: http:// www.ncbi.nlm.nih.gov/pmc/articles/PMC557899/DOI: 10.1136/ bmj.330.7500.1132 PMID: 15891229

30. Arday DR, Kanjarpane DD, Kelley PW. Mumps in the US Army 1980-86: should recruits be immunized?Am J Public Health. 1989;79(4):471-4. DOI: 10.2105/AJPH.79.4.471 PMID: 2494895

31. Rubin SA, Plotkin SA. Mumps vaccine. In: Plotkin S, Orenstein W, Offit P, editors. Vaccines. 6th ed. Philadelphia: Saunders; 2012. p. 419-46.

32. Levine H, Rishpon S, Huerta-Hartal M, Davidovitch N. Preventing mumps outbreaks in confined settings: comprehensive ring vaccination as a containment strategy. Hum Vaccin. 2011;7(12):1389-93. . Available from: http://www. tandfonline.com/doi/abs/10.4161/hv.7.12.18111DOI: 10.4161 / hv.7.12.18111 PMID: 22108037

33. Gouma S, Schurink-Van't Klooster TM, de Melker HE, Kerkhof J, Smits GP, Hahné SJ, et al. Mumps serum antibody levels before and after an outbreak to assess infection and immunity in vaccinated students. Open Forum Infect Dis. 2014;1(3):ofu101. DOI: 10.1093/ofid/ofu101 PMID: 25734169

\section{License and copyright}

This is an open-access article distributed under the terms of the Creative Commons Attribution (CC BY 4.0) Licence. You may share and adapt the material, but must give appropriate credit to the source, provide a link to the licence, and indicate if changes were made.

This article is copyright of the authors, 2016. 